\title{
NGHIÊN CÚU NGUYÊN NHÂN CỦA VẾT NỨT THĂNG ĐÚ'NG XUẤT HIỆN TRÊN CÁC TRỤ CẦU BÊ TÔNG CỐT THÉP DẠNG RẺ QUẠT
}

\author{
NGUYỄN QUANG DŨNG ${ }^{1}$, NGÔ CHÂU PHUOONG ${ }^{2}$ \\ ${ }^{1}$ Khoa Kỹ thuật xây dưng, Truoòng Đại học Công nghiệp Tp.HCM, \\ ${ }^{2}$ Truoòng đại học Giao thông Vận tải-Phân hiệu tại Tp.HCM \\ nguyenquangdung@iuh.edu.vn
}

Tóm tắt. Trụ cầu dạng tường rẻ quạt bê tông cốt thép thường đã được sử dụng rộng rãi trong các cầu vượt đô thị ở các nút giao khác mức tại Việt Nam do có ưu điểm về mỹ quan và tiết kiệm vật liệu. Tuy nhiên trong quá trình thi công cũng như khai thác, loại trụ này đã xuất hiện vết nứt thẳng đứng tại khu vực giữa đỉnh trụ ở nhiều công trình. Bài báo này trình bày kết quả nghiên cứu giải thích nguyên nhân xuất hiện vết nứt thẳng đứng trụ cầu dạng tường rẻ quạt bằng mô hình chống giằng, phương pháp phần tử hữu hạn và đối chiếu với số liệu đo đạc thực tế nhằm đề xuất phương pháp thiết kế phù hợp cho các công trình tương tự trong tương lai.

Từ khóa. Trụ cầu dạng tường rẻ quạt, mô hình chống giằng, sự cố trong xây dựng, nứt trụ cầu dạng tường rẻ quạt.

\section{STUDYING ON THE CAUSES OF THE VERTICAL CRACKS APPEARED ON THE FAN SHAPED REINFORCED CONCRETE PIERS}

\begin{abstract}
The fan-shaped concrete piers have been widely applied in urban crossover bridges in Vietnam due to the advantages of aesthetic and material saving. However, during the construction stage as well as operation stage, vertical cracks occurred on the top of the piers in some bridges. The paper presents the research on the causes appearing the cracks on the fan-shaped concrete pier based on strut tie model, finite element method and comparison with measurement data for proposing a suitable design method for similar bridges in the future.
\end{abstract}

Keywords. Fan-shaped pier, strut and tie model, trouble in construction, cracks on the fan-shaped pier.

\section{1.ĐẠT VẤN ĐỀ}

Trong khoảng 15 năm trở lại đây, ở Thành phố Hồ Chí Minh đã xây dựng nhiều cầu vượt tại các nút giao khác mức và sử dụng kết cấu trụ cầu dạng tường rẻ quạt bê tông cốt thép thường. Dạng trụ cầu này có mỹ quan đẹp và tiết kiệm nguyên vật liệu so với các trụ cầu thân hẹp truyền thống, phù hợp dùng trong các công trình cầu vượt trong đô thị. Tuy nhiên một số cầu sử dụng dạng trụ này như cầu vượt nút giao Khu A- Quận 7 (đường Nguyễn Văn Linh và đường dẫn lên cầu Phú Mỹ), cầu vượt nút QL1 với đường Nguyễn Văn Linh- Bình Chánh, cầu Nguyễn Văn Cừ- Quận 1, cầu vượt trên đường vành đai $2 \ldots$ đã có sự xuất hiện vết nứt ở mặt bên, mặt trên đỉnh trụ và trên ụ chống xô ở các trụ cầu [1]. Thậm chí có 1 cầu trong giai đoạn thi công đã xuất hiện vết nứt theo phương thẳng đứng ở mặt bên và theo phương ngang ở mặt trên đỉnh trụ cầu dạng rẻ quạt.

Bài báo nghiên cứu đánh giá nguyên nhân xuất hiện vết nứt cho một trụ cầu rẻ quạt điển hình ở thành phố Hồ Chí Minh đứng ở khía cạnh thiết kế nhằm rút ra bài học kinh nghiệm trong cho quá trình đào tạo nhân lực, thiết kế, thẩm tra và thẩm định hồ sơ nhằm hạn chế sự xuất hiện vết nứt cho trụ cầu dạng rẻ quạt của các công trình tương tự trong tương lai. 


\section{2. ĐỐI TƯỢNG VÀ PHƯƠNG PHÁP NGHIÊN CỨU}

Trụ cầu dạng tường rẻ quạt của công trình đại diện được nghiên cứu có cấu tạo như hình 1 với chiều cao $\mathrm{H}$ tùy thuộc vị trí của trụ, trụ cầu bằng bê tông cốt thép thường có $\mathrm{f}^{\prime}{ }_{\mathrm{c}}=30 \mathrm{MPa}$, lưới cốt thép mặt trên đỉnh trụ được bố trí là 1 lớp gồm 15 thanh $\Phi 16$, cốt thép chịu nén theo phương đứng bố trí 1 lớp gồm 84 thanh $\Phi 32$ tại chân trụ và 130 thanh tại đỉnh trụ $\Phi 32$, cường độ chịu kéo chảy cốt thép là $\mathrm{f}_{\mathrm{y}}=420 \mathrm{MPa}$ [2].

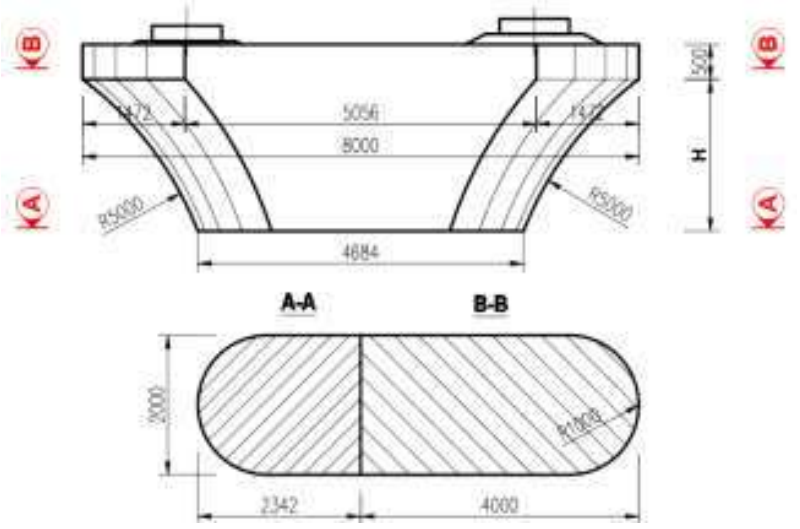

Hình 1. Kích thước trụ cầu dạng tường rẻ quạt điển hình [2]

Trong quá trình thi công, các đơn vị liên quan phát hiện vết nứt thẳng đứng ở mặt bên trụ, vết nứt ngang ở mặt trên thân trụ và trên ụ chống xô như được thể hiện trên hình 2,3 và 4 . Theo kết quả quan trắc vết nứt do các bên liên quan tiến hành, vết nứt xuất hiện theo phương thẳng đứng tại khu vực giữ gối và ụ neo, ở mặt hông trụ bề rộng các vết nứt đo được $0,3 \mathrm{~mm}$ đến $0,4 \mathrm{~mm}$ với độ sâu từ $16 \mathrm{~mm}$ đến $134 \mathrm{~mm}$ và trụ không có chuyển vị bất thường theo cả 3 phương [2].

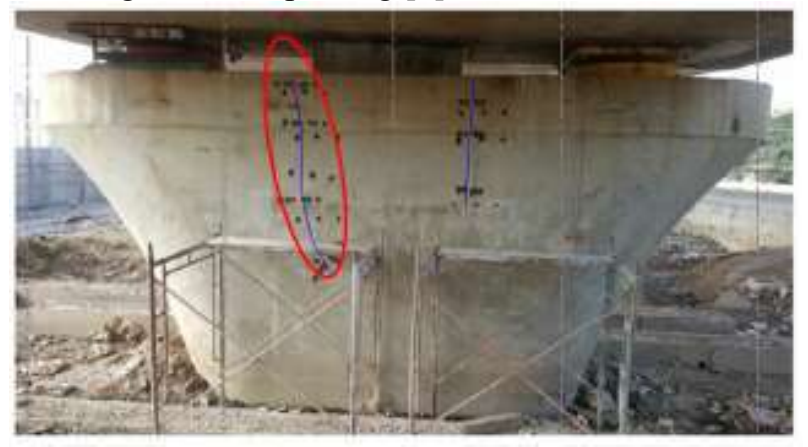

Hình 2. Vết nứt thẳng đứng ở mặt ngoài thân trụ. [2]

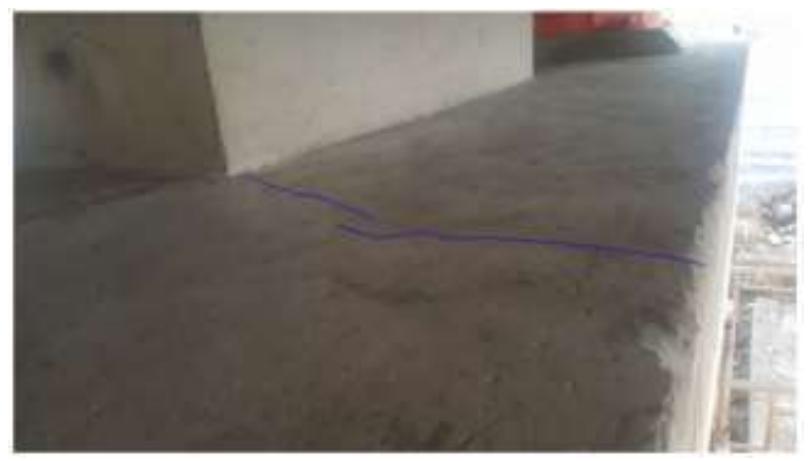

Hình 3. Vết nứt ngang ở mặt trên đỉnh trụ [2] 


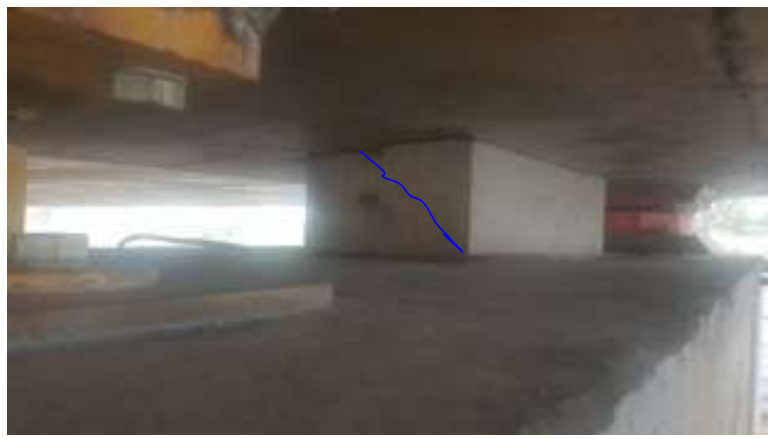

Hình 4. Vết nứt ở trên ụ chống xô. [2]

Các bên liên quan đã rà soát toàn bộ quá trình thi công trụ cầu và kết luận chung là quá trình thi công đã tuân thủ các tiêu chuẩn kỹ thuật áp dụng cho công trình và không xác định được nguyên nhân gây nứt. Đến đây bài toán đặt ra phải xác định được nguyên nhân xuất hiện vết nứt để phòng tránh sự cố đối với các cầu tương tự trong tương lai. Sau khi rà soát lại phương pháp thiết kế, xuất hiện một số điểm cần lưu ý đó là nội lực trong trụ được tính toán theo mô hình cột chữ $\mathrm{T}$ và kiểm toán theo sơ đồ dầm hẫng cho mặt cắt tại ngàm (điểm cách tim gối 1 đoạn là $\mathrm{R} / 3$ với $\mathrm{R}$ là bán kính bo tròn thân trụ) đều đảm bảo chịu lực. Kết quả kiểm toán được thể hiện trong bảng 1 .

Bảng 1. Kết quả kiểm toán sức kháng uốn mặt cắt thẳng đứng của trụ cầu theo điều 5.7.3.2.3 và điều 5.8.2.1 tiêu chuẩn thiết kế 22 TCN 272-05 [2].

\begin{tabular}{|c|c|c|c|c|c|}
\hline Trụ & $\begin{array}{l}\text { Kích thước } \\
\text { mặt cắt }\end{array}$ & $\begin{array}{l}\text { Nội dung } \\
\text { kiểm toán }\end{array}$ & $\begin{array}{l}\text { Nội lực trong } \\
\text { thi công }\end{array}$ & $\begin{array}{l}\text { Khả năng chịu } \\
\text { lực tính toán }\end{array}$ & Kết luận \\
\hline \multirow{2}{*}{$\mathrm{T} 1$} & \multirow{2}{*}{$\square 10,6 \times 2 \mathrm{~m}$} & Moment uốn & $\mathrm{M}_{\mathrm{u}}=813,40$ t.m & $\mathrm{M}_{\mathrm{r}}=5283,30 \mathrm{t} . \mathrm{m}$ & $\mathrm{M}_{\mathrm{r}}>\mathrm{M}_{\mathrm{u}}$ \\
\hline & & Lực cắt & $\mathrm{Q}_{\mathrm{u}}=980,00 \mathrm{t}$ & $\mathrm{Q}_{\mathrm{r}}=11329,77 \mathrm{t}$ & $\mathrm{Q}_{\mathrm{r}}>\mathrm{Q}_{\mathrm{u}}$ \\
\hline \multirow{2}{*}{ T5 } & \multirow{2}{*}{$\square 5,2 \times 2 \mathrm{~m}$} & Moment uốn & $\mathrm{M}_{\mathrm{u}}=637,00$ t.m & $\mathrm{M}_{\mathrm{r}}=1578,29$ t.m & $\mathrm{M}_{\mathrm{r}}>\mathrm{M}_{\mathrm{u}}$ \\
\hline & & Lực cắt & $\mathrm{Q}_{\mathrm{u}}=980,00 \mathrm{t}$ & $\mathrm{Q}_{\mathrm{r}}=5773,68 \mathrm{t}$ & $\mathrm{Q}_{r}>\mathrm{Q}_{\mathrm{u}}$ \\
\hline
\end{tabular}

Ghi chú: (1): Nội lực phát sinh do tải trọng tĩnh tác dụng lên gối là $9800 \mathrm{kN}$.

(2): Khả năng chịu lực (uốn, cắt) theo điều 5.7.3.2.3 và 5.8.2.1 của tiêu chuẩn $22 \mathrm{TCN} 272-05$

Để có luận cứ khoa học đánh giá nguyên nhân gây nứt, bài báo áp dụng phương pháp nghiên cứu thiết kế theo mô hình chống giằng tại điều 5.6.3 của 22 TCN 272-05 để tính toán lượng cốt thép chịu lực mặt trên trụ dạng rẻ quạt và kiểm chứng bằng phần mềm phân tích kết cấu bê tông cốt thép theo phương pháp phần tử hữu hạn.

Mô hình chống giằng được phát triển lần đầu bởi Schlaich (1987), tiếp tục được phát triển bởi Collins và Mitchell (1991) và MacGregor (1992). Năm 1994 phương pháp này lần đầu tiên dược đưa vào bộ tiêu chuẩn thiết kế cầu của $\mathrm{AASHTO}$ và được đưa vào tiêu chuẩn thiết kế kết cấu bê tông của Viện bê tông Mỹ ACI 318-02. Mô hình chống giằng cung cấp một cách tiếp cận hợp lý bằng cách thay thế các kết cấu phức tạp bằng mô hình các thanh dàn đơn giản phù hợp [3].

Theo Tiêu chuẩn thiết kế 22 TCN 272-05 được áp dụng, tại điều 5.13.2.4.1 và 5.13.2.4.2: Với dầm hẫng có chiều dài cánh hẫng $\left(\mathrm{a}_{\mathrm{v}}\right)$ nhỏ hơn chiều cao mặt cắt $(\mathrm{d})$ phải kiểm toán theo theo sơ đồ dầm ngắn hay dầm chìa và phải thiết kế theo mô hình chống giằng [3].

Theo ACI 318-08, khái niệm dầm cao là dầm chịu tải trọng trên một mặt và được đỡ trên mặt đối diện, do đó trong dầm hình thành những thanh chống (chịu nén) giữa tải trọng và gối đỡ và có một trong các đặc điểm sau: (1) tỷ lệ chiều dài nhịp $(l)$ và chiều cao dầm (h) bé hơn hoặc bằng 4 lần; (2) tải trọng tập trung xuất hiện gần vị trí gối đỡ (nằm trong khoảng 2 lần chiều cao dầm tính từ mép của gối đỡ). Khi thiêt kế dầm không tính toán như cấu kiện chịu uốn thông thường mà phải chọn theo một trong các phương pháp: (1) theo quan điểm phân bố biến dạng là phi tuyến hoặc (2) sử dụng mô hình giàn ảo. Phân bố ứng suất trong dầm cao (hình 5 ) phụ thuộc vào tỷ lệ $l / \mathrm{h}$ và khi $l / \mathrm{h} \leq 4$ thì phân bố ứng suất hoàn toàn khác với dầm thông thường [4]. 


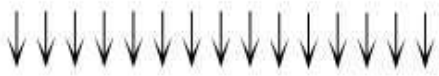

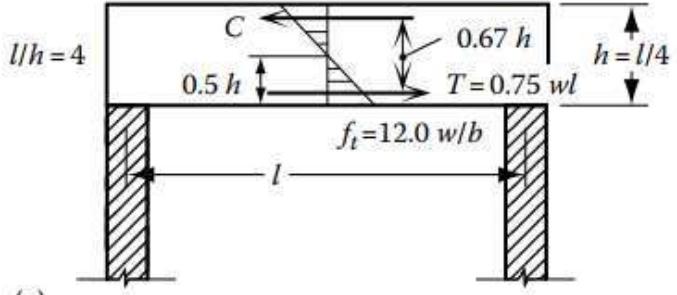

(a)

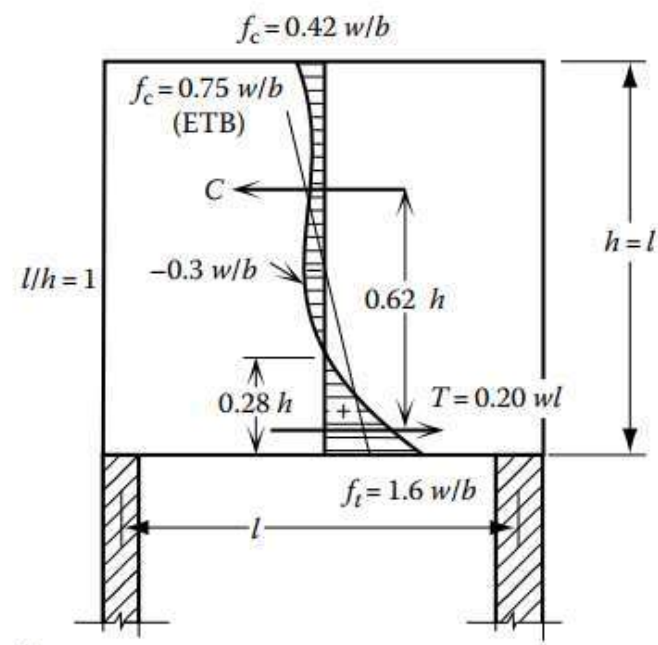

(c)

Hình 5. Phân bố ứng suất ứng với chiều cao dầm,

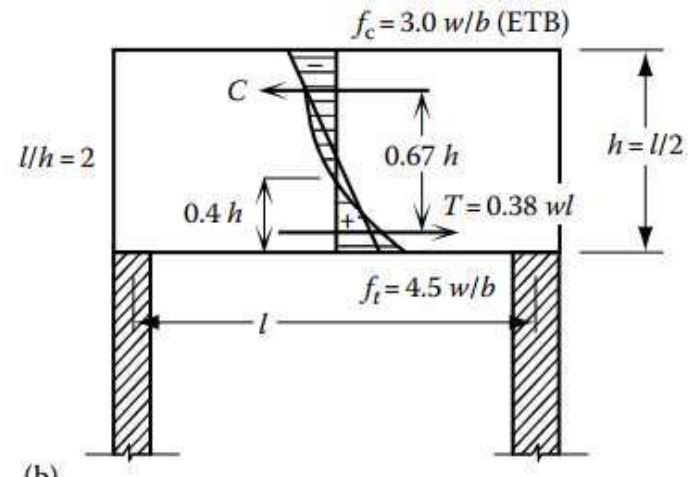

(b)

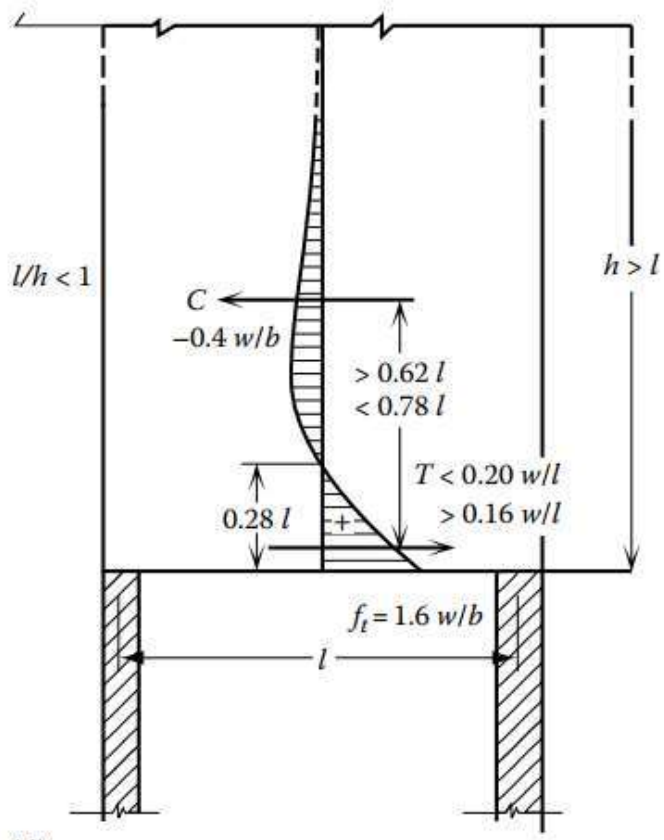

(d)

Cấu tạo các trụ cầu rẻ quạt thể hiện tại hình 1 , đến đây bước đầu có thể khẳng định việc áp dụng phương pháp thiết kế thông thường của đơn vị thiết kế cho trụ cầu rẻ quạt (hình 1) là chưa phù hợp mà phải áp dụng mô hình chống - giằng hoặc phương pháp phần tử hữu hạn để thiết kế.

\section{3. ĐÁNH GIÁ NGUYÊN NHÂN GÂY NỨT TRỤ CẦU DẠNG TƯờnG RẺ QUẠT}

\subsection{Tính toán lượng cốt thép cần thiết bố trí cho trụ theo mô hình chống giằng}

Sơ đồ chống giằng của trụ cầu được xây dựng trên hình 6 với $\mathrm{H}=2,679 \mathrm{~m}$, bê tông thân trụ có $\mathrm{f}^{\prime}{ }_{\mathrm{c}}=30 \mathrm{MPa}$. Cốt thép có cường độ kéo chảy $\mathrm{f}_{\mathrm{y}}=420 \mathrm{MPa}$, lớp cốt thép chịu kéo trên đỉnh trụ được mô tả bằng thanh chịu kéo 1 cách mặt trên đỉnh trụ $104 \mathrm{~mm}$ gồm $15 \Phi 16$, vị trí của thanh chịu nén 2 và 3 được xác định thông qua trị số cánh tay đòn nội lực là $J_{d}=0,6 . l=2,072 \mathrm{~m}$, góc xiên $\theta=55^{\circ} 37^{\prime} 58^{\prime \prime}$ và $b_{1}=1,26 \mathrm{~m}$, $b_{2}=2,166 m$ theo nguyên tắc ứng suất nén do tải trọng phân bố đều lên chân trụ [4], [5]. Tải trọng tác dụng lên 1 gối cầu theo trạng thái giới hạn cường độ được tính toán bằng phần mềm MIDAS, trong giai đoạn thi công (chưa hợp long 2 nhịp giữa) là $\mathrm{P}=9800 \mathrm{kN}$ và trong giai đoạn khai thác $\mathrm{P}=17800 \mathrm{kN}$ thông qua gối cầu có kích thước $1 \mathrm{~m} \times 0,7 \mathrm{~m}$. 


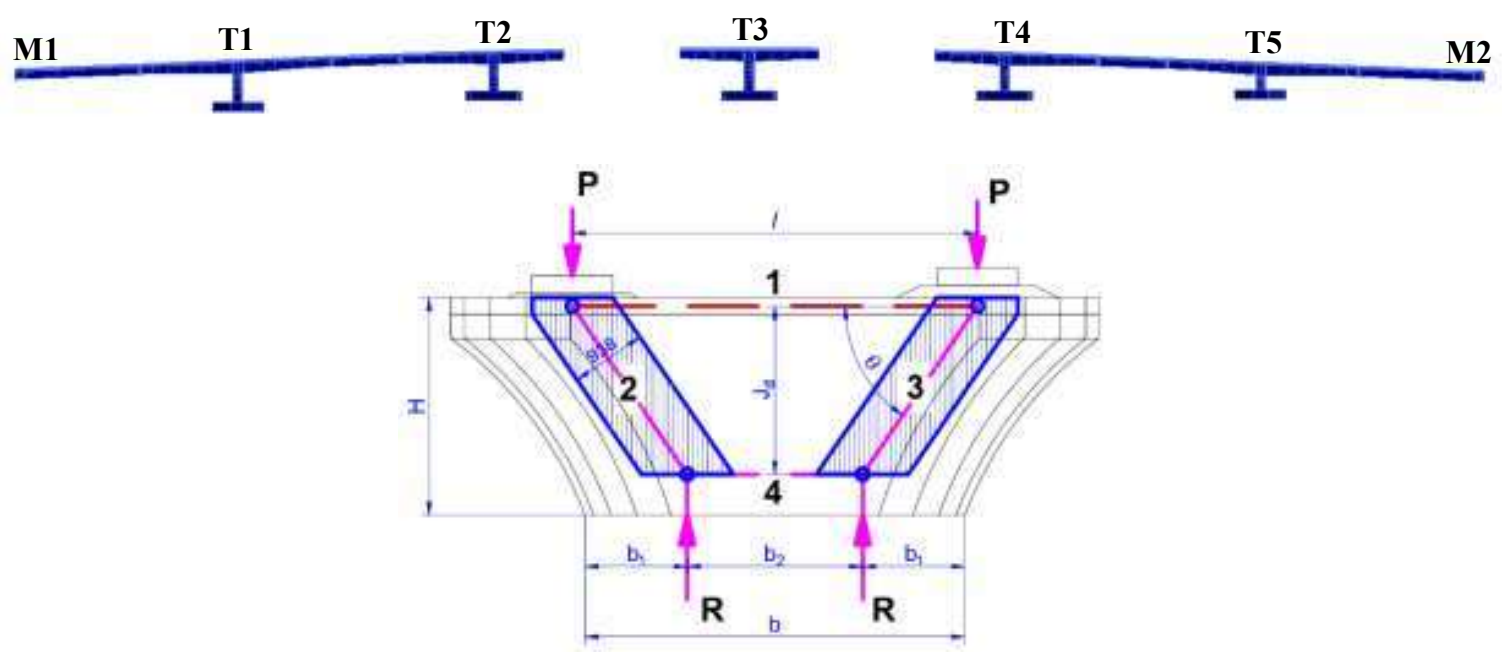

Hình 6. Mô hình tính phản lực gối và mô hình chống giằng của trụ cầu $\mathrm{T} 1$ cho trên hình 1 .

Nội lực trong các thanh được tính toán từ điều kiện cân bằng lực tại các nút, thu được kết quả như trên bảng 2 .

Bảng 2. Kết quả tính nội lực và ứng suất các thanh theo sơ đồ chống giằng

\begin{tabular}{|c|l|r|r|r|}
\hline \multirow{2}{*}{ Thanh } & \multirow{2}{*}{ Công thức } & \multicolumn{2}{|c|}{ Nội lực (kN) } & \multirow{2}{*}{ Ghi chú } \\
\cline { 3 - 4 } & & \multicolumn{1}{|c|}{ Thi công } & \multicolumn{1}{|c|}{ Khai thác } & \\
\hline 1 & $T_{1}=P . \cot g(\theta)$ & 6.702 & 12.173 & \\
\hline 2 và 3 & $C_{2}=C_{3}=-P / \sin (\theta)$ & -11.873 & -21.564 & \\
\hline 4 & $C_{4}=-P . \cot g(\theta)$ & -6.702 & -12.173 & \\
\hline
\end{tabular}

Lực kéo trong thanh giằng 1 không bố trí dự ứng lực phải thỏa mãn điều kiện:

$$
T_{1} \leq \Phi \cdot A_{s t} \cdot f_{y}
$$

\section{trong đó:}

$\Phi=0,9$ là hệ số sức kháng kéo đối với bê tông cốt thép thường [6];

$\mathrm{f}_{\mathrm{y}}$ là cường độ kéo chảy của cốt thép.

Lượng cốt thép chịu kéo tối thiểu của thanh 1 là:

$$
A_{s t}^{\min }=\frac{T_{1}}{\Phi \cdot f_{y}}
$$

Lực nén trong thanh chống 2,3 có bố trí cốt thép phải thỏa mãn điều kiện:

$$
C_{2}=C_{3} \leq \Phi \cdot\left[f_{c u} \cdot A_{c c}+f_{y} \cdot A_{s c}\right]
$$

trong đó:

$\mathrm{A}_{\mathrm{cc}}$ là diện tích bê tông hữu hiệu của thanh chống;

$\mathrm{A}_{\mathrm{sc}}$ là diện tích cốt thép trong thanh chống;

$\Phi=0,7$ là hệ số sức kháng nén đối với bê tông cốt thép thường [3].

Khi đó lượng cốt thép tối thiểu trong thanh chống 2, 3 là:

$$
A_{s c}=\frac{1}{f_{y}} \cdot\left(\frac{C_{2}}{\Phi}-f_{c u} \cdot A_{c c}\right)
$$

trong đó: 


$$
\begin{aligned}
& f_{c u}=\frac{f_{c}}{0,8+170 \cdot \varepsilon_{1}} \leq 0,85 \cdot f_{c} \text { là ứng suất nén giới hạn trong thanh chống; } \\
& \varepsilon_{1}=\varepsilon_{s}+\left(\varepsilon_{s}+0,002\right) \cdot \cot ^{2}(\theta) ;
\end{aligned}
$$

$\varepsilon_{\mathrm{s}}$ là biến dạng kéo trong bê tông theo hướng giằng chịu kéo.

Kết quả tính toán lượng cốt thép tối thiểu được thể hiện trong bảng 3.

\begin{tabular}{|c|c|c|c|c|}
\hline \multirow{2}{*}{ Thanh } & \multicolumn{2}{|c|}{ Lượng cốt thép tối thiểu $\left(\mathrm{cm}^{2}\right)$} & \multirow{2}{*}{$\begin{array}{c}\text { Lượng cốt thép theo } \\
\text { thiết kế }\left(\mathrm{cm}^{2}\right)\end{array}$} & \multirow{2}{*}{ Đánh giá } \\
\hline & Thi công & Khai thác & & \\
\hline 1 & 177,30 & 322,04 & 30,16 & Thiếu cốt thép \\
\hline 2 và 3 & 313,00 & 642.62 & 101,43 & Thiếu cốt thép \\
\hline
\end{tabular}

Bảng 3. Kết quả tính lượng cốt thép tối thiểu trong giai đoạn thi công và khai thác theo mô hình chống giằng

Nhận xét: Luợng thép của thanh giằng 1 đã bố trí thiếu dẫn đến thanh giằng không đủ khả năng chịu lưc và làm giảm ứng suất giới hạn trong bê tông $f_{c u}$ của thanh chống 2 và 3 , diều này dẫn đến việc xuất hiện vết nứt gần thẳng đứng trên thân trư nhu hình 2. Trong truờng hợp bố trí đủ lượng thép cho thanh giằng 1 thì lương cốt thép cho thanh chống 2 và 3 cũng đảm bảo thỏa mãn do úng suất giới hạn trong thanh chống $f_{c u}$ tăng lên.

\subsection{Phân tích sự làm việc của trụ cầu rẻ quạt bằng phần mềm ATENA.}

Để kiểm chứng kết quả tính toán bằng mô hình chống giằng, tác giả tiến hành mô phỏng trụ cầu có các thông số cầu tạo như đã mô tả tại mục 3.1 ở trên bằng phần mềm chuyên dụng ATENA. Bê tông được mô phỏng là vật liệu biến dạng phi tuyến ba chiều (hình 7) và cốt thép được mô phỏng là vật liệu biến dạng theo mô hình song tuyến tính (hình 8).

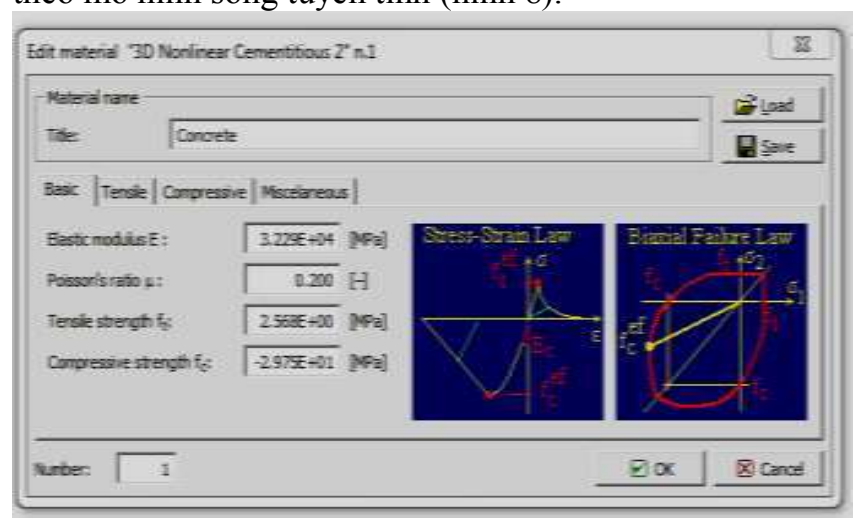

Hình 7. Mô hình vật liệu bê tông

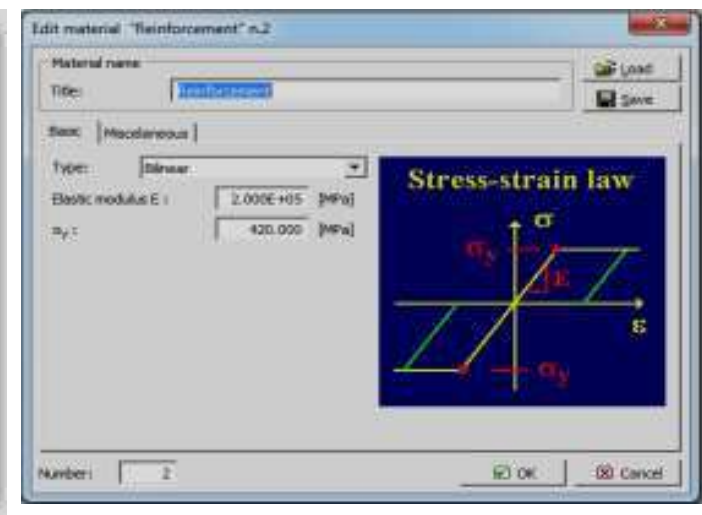

Hình 8. Mô hình vật liệu cốt thép

Tải trọng tác dụng lên kết cấu được mô hình dưới dạng áp lực tác dụng lên bề mặt tấm kê có kíeh thước $0,7 \mathrm{x} 1 \mathrm{~m}$ với độ lớn là $14 \mathrm{MPa}$ tương ứng với độ lớn $9800 \mathrm{kN}$ trong giai đoạn thi công. Tải trọng này được chia thành 10 bước tác dụng lên kết cấu, kết quả mô phỏng được thể hiện trên hình 9 đến hình 12 .

Theo kết quả mô phỏng, do lượng cốt thép quá ít dẫn đển ứng suất trong cốt thép đạt đến giới hạn chảy $420 \mathrm{MPa}$ (hình 9). Khi ứng suất trong cốt thép đạt giới hạn chảy, toàn bộ ứng suất kéo chuyển sang bê tông chịu dẫn đến ứng suất chính lớn nhất trong bê tông đạt đến $3,7 \mathrm{MPa}$ (hình 10 ) tương ứng với biến dạng theo phương chính là $2,25 \times 10^{-3}$ (hình 11 ) và bề rộng vết nứt là $0,62 \mathrm{~mm}$ (hình 12 ). Úng suất bê tông trong thân trụ vượt quá giới hạn kháng nứt của bê tông thân trụ là $0,8 \cdot f_{r}=0,8 \cdot 0,6 \sqrt{f_{c}}=2,761 M P a$ dân đến phát sinh vết nứt theo hướng thẳng đứng. 


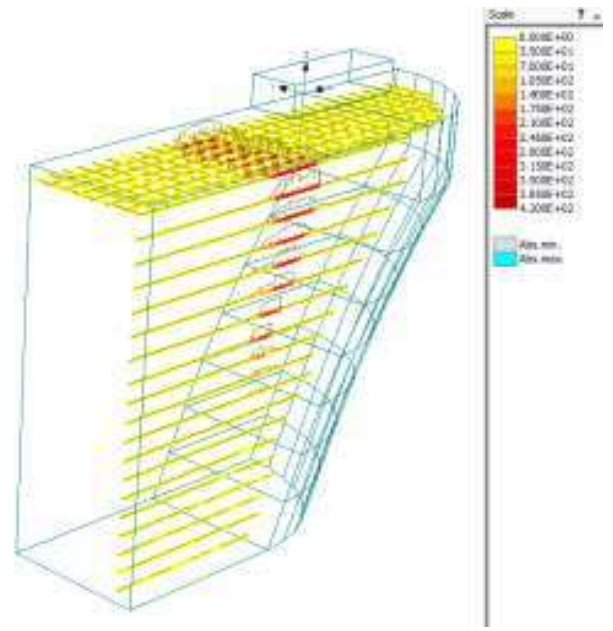

Hình 9. Kết quả ứng suất kéo trong lưới cốt thép, ứng suất trong cốt thép đạt đến giới hạn chảy 420MPa.

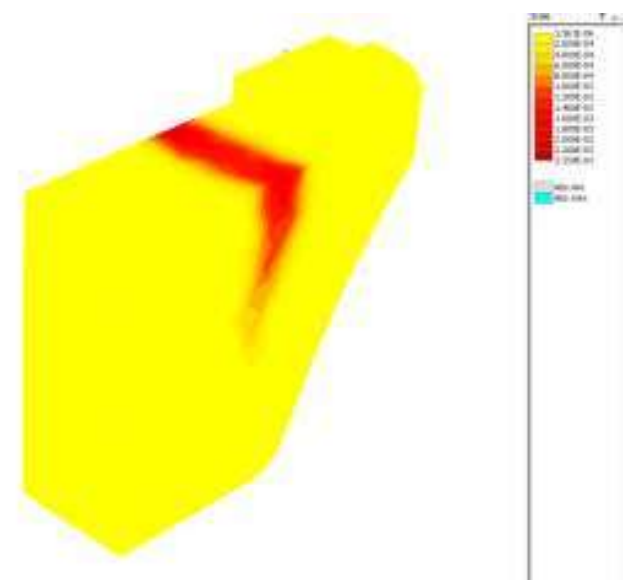

Hình 11. Biến dạng lớn nhất của bê tông trụ đạt $2,259 \times 10^{-3}$.
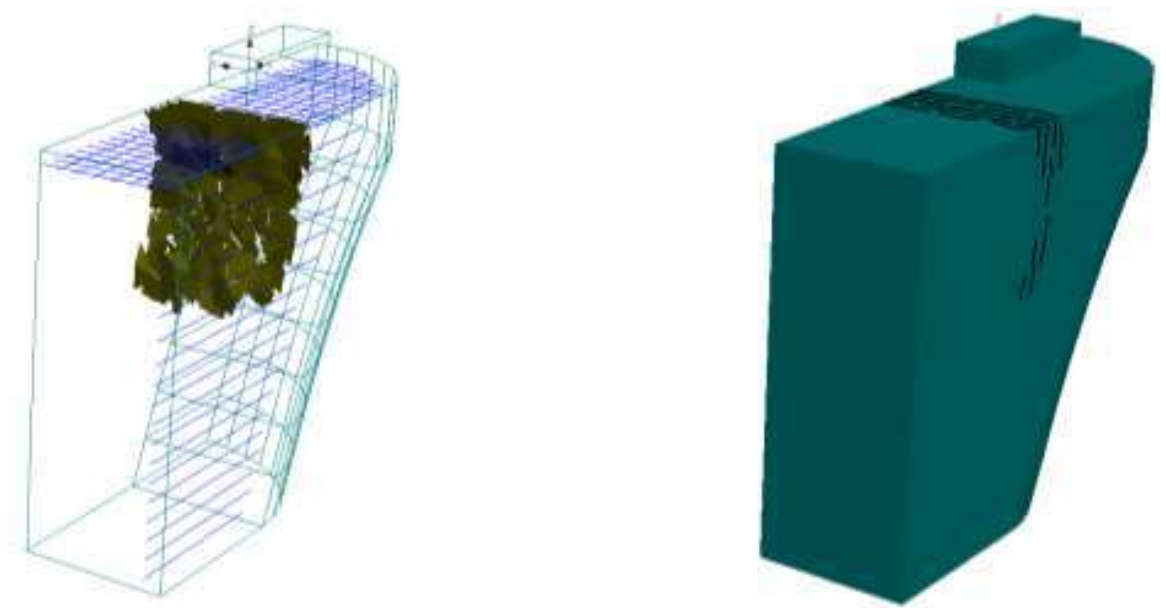

Hình 12. Cấu trúc vết nứt trong bê tông thân trụ, độ mở rộng vết nứt lớn nhất trên đỉnh trụ đạt đến $0,62 \mathrm{~mm}$ 
So với kết quả tính toán mô phỏng bằng phần mềm ATENA và kết quả tính toán theo mô hình chống giằng là phù hợp. Điều này khẳng định nguyên nhân phát sinh vết nứt là do thiết kế lớp cốt thép chịu kéo mặt trên trụ cầu bị thiếu. Để xử lý vấn đề thiếu cốt thép này có thể áp dụng công nghệ dự ứng lực ngoài bằng cáp dự ứng lực hoặc thanh thép cường độ cao Macalloy, vấn đề này sẽ được bàn luận trong bài báo khác.

\section{KẾT LUẬN}

Đa phần các hồ sơ thiết kế đã áp dụng phương pháp mặt cắt tính toán truyền thống hoặc có thể đã bỏ qua tính toán mà chỉ bố trí cốt thép theo kinh nghiệm hay các thiết kế mẫu của trụ tường thân hẹp có hình dạng gần tương tự.... Qua kết tính toán, phân tích bằng mô hình chống giằng và kiểm chứng bằng phương pháp phần tử hữu hạn của bài báo có thể kết luận nguyên nhân nứt trụ cầu bê tông cốt thép thường có dạng tường rẻ quạt là do áp dụng phương pháp tính toán thiết kế chưa phù hợp.

Từ những phân tích, tính toán chỉ ra rằng khi thiết kế loại trụ cầu dạng rẻ quạt phải áp dụng mô hình chống giằng là hết sức cần thiết do tại đây trường ứng suất nhiễu loạn nên việc áp dụng phương pháp thiết kế truyền thống là không an toàn.

Phương pháp tính toán thiết kế theo mô hình chống giằng còn khá mới. Mặt khác, trong tiêu chuẩn thiết kế cầu hiện hành đề cập còn sơ sài, nên dẫn đến những sự cố đáng tiếc trong thiết kế. Điều này cho thấy sự cần thiết của việc cập nhật chương trình đào tạo của các trường đại học và các cơ quan nghiên cứu; đối các cơ quan tư vấn thiết kế, tư vấn thẩm tra và quản lý nhà nước là đây là kinh nghiệm tham khảo để giải quyết các bài toán thực tế nhằm hạn chế các sự cố tương tự trong tương lai.

\section{TÀI LIỆU THAM KHẢO}

[1]. Công ty TNHH Tư vấn thiết kế BR, Kết quá khảo sát các cầu vuoọt nút giao khu A, cầu nút qiao QL1A-Nguyễn Văn Linh, cầu Nguyễn Văn Cù và cầu vuợt trên đường vành đai 2, 2017.

[2]. Công ty cổ phần UTC2, Báo cáo đánh giá kết quả kiểm toán độc lập tru cầu rẻ quạt và giải pháp tăng cuờng, 2018.

[3]. Bộ Giao thông vận tải, Tiêu chuẩn thiết kế cầu 22 TCN 272-05, 2005.

[4]. Bungale S. Taranath, Reinforced concrete design of tall buildings, CRC Press - Taylor \& Francis Group, 2010.

[5]. Nguyễn Viết Trung, Dương Tuấn Minh, Nguyễn Thị Tuyết Trinh, Tính toán kết cấu bê tông cốt thép theo mô hình giàn ảo, NXB Xây dựng, 2005.

Ngày nhận bài: 03/07/2019

Ngày chấp nhận đăng: 12/11/2019 